Успехи физ. мет. / Usp. Fiz. Met. 2015, т. 16, сс. 1-22 Оттиски доступны непосредственно от издателя Фотокопирование разрешено только в соответствии с лицензией (с) 2015 ИМФ (Институт металлофизики им. Г. В. Курдюмова НАН Украины)

Напечатано в Украине.

PACS numbers: 46.25.Hf, 62.20.fg, 64.70.kd, 65.40.De, 81.30.Kf, 81.40.Jj

\title{
Thermoelastic Behaviour, Hysteresis, and Dissipative Forces in Thermodynamics of Martensitic Transformations
}

\author{
O. A. Likhachev and Yu. M. Koval
}

G. V. Kurdyumov Institute for Metal Physics, N.A.S. of Ukraine, 36 Academician Vernadsky Blvd., UA-03680 Kyiv-142, Ukraine

In the present article, a set of thermodynamic problems of the temperature-induced thermoelastic martensitic transformation is discussed. It is shown that the constitutive thermodynamic force balance equations describing the temperature dependence of martensite volume fraction on the global hysteresis cycle can be directly derived from the energy conservation law where the additional irreversible work is taken into account. Resulting force balance occurs between the classical ('chemical') driving force, on the one hand, and the so-called nonchemical forces representing the elastic, interfacial and other energy contributions, on the other hand. The procedure of finding the nonchemical contributions from the calorimetric experiments is developed and applied to the analysis of DSC measurements for the $\mathrm{CuZnAl}$ and $\mathrm{CuAlNi}$ shape-memory alloys. Finally, the problem of thermoelastic martensitic transformation is discussed on the basis of the microscopic theoretical approach.

В даній роботі обговорюється ряд проблем термодинаміки термічно індукованих термопружніх мартенситних перетворень. Показано, що основна система рівнянь балансу термодинамічних сил, що описує температурну залежність об'ємної частки мартенситу, може бути одержана безпосередньо із закону збереження енергії, де додатково враховано ефекти необоротньої роботи проти внутрішніх дисипативних сил. Загальний баланс термодинамічних сил відбувається між класичними («хімічними») рушійними силами, з одного боку, та так званими нехімічними силами, обумовленими пружніми, міжфазними й іншими енергетичними внесками, з іншого. Розроблено процедуру визначення таких нехімічних внесків на основі калориметричних експериментів, яку застосовано для аналізи калориметричних даних в стопах з ефектом пам'яті форми CuZnAl та CuAlNi. Насамкінець, проблеми термопружніх мартенситних перетворень обговорюються на основі мікроскопічного теоретичного підходу.

В данной работе обсуждается ряд проблем термодинамики термически 
индуцированных термоупругих мартенситных превращений. Показано, что основная система уравнений баланса термодинамических сил, которая описывает температурную зависимость объёмной доли мартенсита, может быть получена непосредственно из закона сохранения энергии, где дополнительно учтены эффекты необратимой работы против внутренних диссипативных сил. Общий баланс термодинамических сил осуществляется между классическими («химическими») движущими силами, с одной стороны, и так называемыми нехимическими силами, обусловленными упругими, межфазными и другими энергетическими вкладами, с другой. Разработана процедура определения таких нехимических вкладов на основе калориметрических экспериментов, которая применена для анализа калориметрических данных в сплавах с эффектом памяти формы CuZnAl и $\mathrm{CuAlNi.} \mathrm{B} \mathrm{заключение,} \mathrm{проблемы}$ термоупругих мартенситных превращений обсуждаются на основе микроскопического теоретического подхода.

Keywords: shape-memory alloys, martensitic transformation, hysteresis, thermoelastic equilibrium.

(Received December 29, 2014)

\section{INTRODUCTION}

As known, during the cycle of martensitic transformation the shape-memory alloys (SMA) run a sequence of heterophase states. In particular, the fraction of martensitic phase increases continuously and then returns back on heating showing a definite temperature hysteresis. At each stage both, the direct and the reverse transformation the microstructure of SMAs consists of great number of plate-like martensitic crystals in austenitic matrix appearing and growing on cooling and shrinking and disappearing on heating continuously and simultaneously with corresponding temperature change. Started from the works by Kurdyumov and Kurdyumov \& Khandros [1-3] on the possibility of the thermoelastic equilibrium during the martensitic transformation in shape-memory alloys, this problem still remain very important for the martensitic transformation physics. During the past time, the great number of problems was a subject for extended discussions and developments in the thermodynamics of thermoelastic martensitic transformations in shape-memory materials for the past time [4-18].

Thermodynamic potentials dependent on the volume fraction of martensitic phase have been first introduced and analysed by Pascal \& Monasevich [11, 12], who postulated existence of two fraction dependent Gibbs free energy potentials representing direct and reverse martensitic transformation, respectively. They also have derived the constitutive thermodynamic force balance equations describing the 
temperature dependence of martensite volume fraction on the global hysteresis cycle additionally assuming the possibility to minimize these, strictly speaking, non-equilibrium potentials. Several other authors have used a similar way. A few problems arise from such a consideration. First, the possibility to consider the configuration dependent thermodynamic functions to be dependent only on the martensite fraction can be physically reasonable if the microscopic configuration sequence passed during direct martensitic transformation will remain the same for reverse transformation too. Such a 'microscopic reversibility' principle has been qualitatively formulated by Olson \& Cohen [7, 8], who pointed out that growth and shrinkage of the martensitic plates take place in a well-defined sequential order and the first plates formed on cooling being the last ones to disappear on heating. Secondly, the introduction of the nonequilibrium Gibbs free energies containing dissipative (friction) terms and especially the application of minimization principle to them can be, in general, a source for incorrect physical conclusions. And finally, a traditional scheme of splitting of the fraction dependent thermodynamic potentials into a pure chemical and nonchemical (elastic) components can be practically useful (in sense of their determination from the experiment) only if the pure chemical equilibrium temperature value $T_{0}$ were known before. However, discussions on the definition and location of $T_{0}$ that have been done by different authors $[9,10]$ just confirm the impossibility to find this quantity directly from the experiments on the temperature induced transformation.

In the present report (accepting in general an idea on the fraction dependent potentials and assuming that the "microscopic reversibility' principle as a possible background of this idea takes place), the more accurate derivation of the thermodynamic force balance equations using directly the first and second Thermodynamics Laws is given. Such a way gives a possibility to avoid the above-mentioned difficulties connected with the possible incorrectness of the free energy minimization procedure in presence of dissipative forces. Secondly, taking into account the problem of direct measurement of $T_{0}$, we propose to realize another splitting scheme for the fraction dependent potentials (internal energy or enthalpy) into the pseudochemical, linearly dependent on the martensite fraction, term and residual nonchemical energy that both can be found experimentally. This procedure gives a possibility to exclude the $T_{0}$-problem from the consideration. Finally, the proposed scheme is applied to the thermodynamic analysis of the temperature induced martensitic transformation in a few copper-based shape-memory alloys to investigate their thermodynamic characteristics with using DSC measurement data. 


\section{ENERGY BALANCE DURING A CYCLE OF THERMOELASTIC TRANSFORMATION}

The following analysis is based on the first and second Thermodynamics Laws that can be represented as follows:

$$
d U(z, T)=T d S(z, T)-P d V(z, T)-d A_{\mathrm{dis}}, \quad d Q=T d S(z, T),
$$

where $U, S$, and $V$ represent the total molar amounts of the internal energy, entropy and molar volume of the martensite + austenite heterophase mixture. $T$ and $P$ are the absolute temperature and pressure. $d A_{\mathrm{dis}}>0$ denotes the elementary irreversible work responsible for hysteresis and $d \boldsymbol{Q}$ is the heat flow obtained during the infinitesimal martensitic fraction $(z)$ change. Practically, because the most of thermoelastic shape-memory alloys usually show very small volume change, one can neglect hereafter the term $P d V$ in Eq. (1), or include it into consideration replacing the internal energy by the enthalpy in left side of this equality. Further, we will neglect for simplicity the $P d V$ term.

The relative fraction of martensitic phase $z(T)$ is one of the most representative macroscopic thermodynamical variables. Due to the temperature hysteresis, the temperature dependence of this variable can be represented by the main hysteresis cycle consisting from two-temperature dependent functions $z_{-}(T)$ for cooling and $z_{+}(T)$ for heating, respectively. The energy conservation law must be fulfilled at each point of this main loop. It is expected (as a result of 'microscopic reversibility hypothesis') that the main thermodynamic functions such as the internal energy $U$ and entropy $S$ of heterophase martensite + austenite system must be dependent on the relative volume fraction and temperature. Most of authors usually represent the total fraction dependent internal energy (or enthalpy) as consisting from two terms. The first one is mainly chosen and treated as completely chemical component, so as the additional term is always considered as the total amount of nonchemical energy stored at the current stage of transformation. In the present paper, we propose (to avoid the problem connected with definition of $T_{0}$ ) to split the total internal energy into the pseudo-chemical component and residual fraction dependent nonchemical energy extracting the linearly dependent part from the total nonchemical energy term and including it additionally to the chemical component. Accordingly, in this case, the total internal energy $U(T, z)$ can be represented as follows:

$$
\begin{gathered}
U(z, T)=(1-z) U_{a}^{0}(T)+z U_{m}^{1}(T)+\varphi(z) \\
U_{a}^{0}(T)=U(0, T), U_{m}^{1}(T)=U(1, T)
\end{gathered}
$$


Here, we have defined the energies $U_{a}^{0}(T)$ and $U_{m}^{1}(T)$ of the completely transformed austenitic and martensitic phases through the total energy $U(z, T)$ of heterophase system taken at $z=0$ and $z=1$ values of the martensite fraction. The nonchemical energy $\varphi(z)$ is defined as a residual part between the total energy and its pseudochemical component that is linearly dependent on the martensite $z$ and austenite $1-z$ fractions. As a result, the energy of the completely martensitic state $U_{m}^{1}(T)$ will always contain (additionally to a pure chemical component) a constant nonchemical term representing the elastic as well as the inter-variant interface energy stored in the completely martensitic state. The austenite energy $U_{a}^{0}(T)$ will contain only the chemical component. One can easily check that due to such a separation scheme the residual nonchemical potential will always satisfy zero conditions $\varphi(0)=\varphi(1)=0$ in the completely austenitic and martensitic states. The entropy of austenite + martensite system can be defined as follows:

$$
S(z, T)=(1-z) S_{a}(T)+z S_{m}(T),
$$

where $S_{a}(T)$ and $S_{m}(T)$ are molar entropies of austenite and martensite, respectively.

Another important quantities that must be considered in the thermodynamics of martensitic transformation are the dissipative work and friction forces representing the irreversible energy loses connected, in general case, with the irreversible motion of interphase and inter-variant boundaries and responsible for the hysteresis effects. These can be defined as

$$
d A_{\mathrm{dis}}= \pm F_{\mathrm{dis}}(z) d z, d A_{\mathrm{dis}} \geq 0 .
$$

Here, the dissipative work $d A_{\text {dis }}$ is always positively defined due to the second thermodynamics law and represents the elementary energy dissipation work caused by the martensite-austenite intervariant boundary displacements during the small change $(d z)$ of martensite fraction. Evidently, $F_{\text {dis }}(z) \geq 0$ and can be interpreted as a generalized dissipative (friction) force producing this irreversible work. So as the dissipative work must be always positive, the signs $(+)$ must be chosen for direct $(d z \geq 0)$ and $(-)$ for reverse transformation, respectively. In a partial case of single interface, the friction force is expected to be a constant independent on the fraction, but in the general case of the multiple interfaces, a similar dependence cannot be excluded. It should be also noted, that no dissipation is expected in the completely austenitic and martensitic states. Therefore, the energies and entropies of austenite and martensite must satisfy usual relationships of non-dissipative thermodynamics: 


$$
d U_{a}^{0}(T)=T d S_{a}(T), d U_{m}^{1}(T)=T d S_{m}(T) .
$$

Taking into account expressions for $U(z, T), S(z, T)$ and $d A_{\text {dis }}$ and substituting them into the Eq. (1) representing the first Thermodynamics Law, one can obtain two main constitutive equations:

$$
\Delta U_{p}(T)-T \Delta S(T)=-\frac{d \varphi(z)}{d z} \pm F_{\mathrm{dis}}(z),
$$

('plus' (+) for heating, while 'minus' (-) for cooling) that give the thermodynamic forces balance for the direct and reverse transformations that is consistent with both the first and the second Thermodynamic Laws. Here, $\Delta U_{p}(T)=U_{m}^{1}(T)-U_{a}^{0}(T)$ and $\Delta S(T)=S_{m}(T)-$ $-S_{a}(T)$ represent in general case the temperature dependent differences of the internal energies and entropies between the martensitic and austenitic states, correspondingly. As follows from the detailed analysis, one can neglect the temperature dependence of these differences and consider them as constants if only the heat capacity difference between the martensite and austenite to be small enough. In this case, the two balance equations determining the transformation paths for the direct $T_{-}(z)$ and reverse $T_{+}(z)$ transformations can be written as follows:

$$
\begin{aligned}
& \Delta S T_{-}(z)=\Delta U_{p}+\frac{d \varphi(z)}{d z}+F_{d i s}(z), \text { for direct } d z \geq 0, \\
& \Delta S T_{+}(z)=\Delta U_{p}+\frac{d \varphi(z)}{d z}-F_{d i s}(z), \text { for direct } d z \leq 0 .
\end{aligned}
$$

Taking a half-sum of these equations, one can obtain the relationship for the definition of the pseudo-chemical transformation heat flow and nonchemical energy:

$$
\Delta S T_{\mathrm{eq}}(z)=\Delta U_{p}+\frac{d \varphi(z)}{d z}, \text { where } T_{\mathrm{eq}}(z)=\frac{1}{2}\left(T_{+}(z)+T_{-}(z)\right) .
$$

Here, $T_{\text {eq }}(z)$ obviously represents the non-dissipative (hysteresisless) thermoelastic equilibrium curve. Integration of this equation by $z$ from 0 to 1 together with zero boundary conditions $\varphi(0)=\varphi(1)=0$ gives the expression for the pseudo-chemical transformation heat flow and the partial integration from 0 to $z$ represents the nonchemical energy as follows:

$$
\Delta U_{p}=\Delta S \int_{0}^{1} d z T_{\mathrm{eq}}(z)=\Delta S T_{0_{p}}, \varphi(z)=\Delta S \int_{0}^{z} d z^{\prime}\left(T_{\mathrm{eq}}\left(z^{\prime}\right)-T_{0_{p}}\right) .
$$

Here, the pseudo-chemical equilibrium temperature $T_{0 p}$ is defined as 


$$
T_{0 p}=\int_{0}^{1} d z T_{\mathrm{eq}}(z)
$$

As follows from this equation, its value is expressed as the average taken from the fraction dependent thermoelastic equilibrium curve and can be always found from the experiment by the measurement of the temperature dependence on the martensite fraction during the main hysteresis cycle according to Eqs. (10) and (12). It is also interesting that according to Eq. (11), $T_{0 p}$ and $\Delta U_{p}$ must satisfy the relationship similar to that as $T_{0}$ and $\Delta U$ in the case of pure chemical equilibrium. However, because $\Delta U_{p}$ always differs from the corresponding chemical value $\Delta U$ by a positive constant nonchemical energy stored in completely martensitic state, one can expect that $T_{0 p}$ will have the lover value than $T_{0}$.

The generalized dissipative force and its dependence on the martensite fraction can also be easily found from the system of balance equations (see Eqs. (8) and (9)) by taking the half-difference between them:

$$
F_{\text {dis }}(z)=-\frac{1}{2} \Delta S\left(T_{+}(z)-T_{-}(z)\right) .
$$

These equations give the necessary background to determine the pseudo-chemical transformation heat value, nonchemical energy and friction force from the calorimetric experiments on the transformation entropy and martensite fraction vs. temperature measurement discussed in the next section.

\section{CALORIMETRIC EXPERIMENTS AND RESULTS}

Two copper-based polycrystalline shape-memory alloys have been investigated by using heat flow measurement on the differential scanning calorimeter 'Perkin Elmer' and analysed in accordance to the above-proposed scheme. The first one denoted here as $(A)$ was the $56 \mathrm{mg}$ sample of $\mathrm{CuZnAl}$ alloy prepared from the round crosssection wire extruded and subjected to 5 min heat treatment at $800^{\circ} \mathrm{C}$ and then quenched into the water at room temperature. The $48 \mathrm{mg}$ sample of $\mathrm{CuAlNi}$ alloy $(B)$ has been prepared from the previously hot rolled at $850^{\circ} \mathrm{C}$ and quenched into the water at room temperature, which then was aged during $60 \mathrm{~min}$ and cooled on air at room temperature [16]. After the heat treatment, the DSC heat flow measurements have been carried out. Corresponding data obtained after a few stabilizing cycles of the martensitic transformation (that have been made to achieve a good reproducibility) are represented in Figs. 1 and 2. 


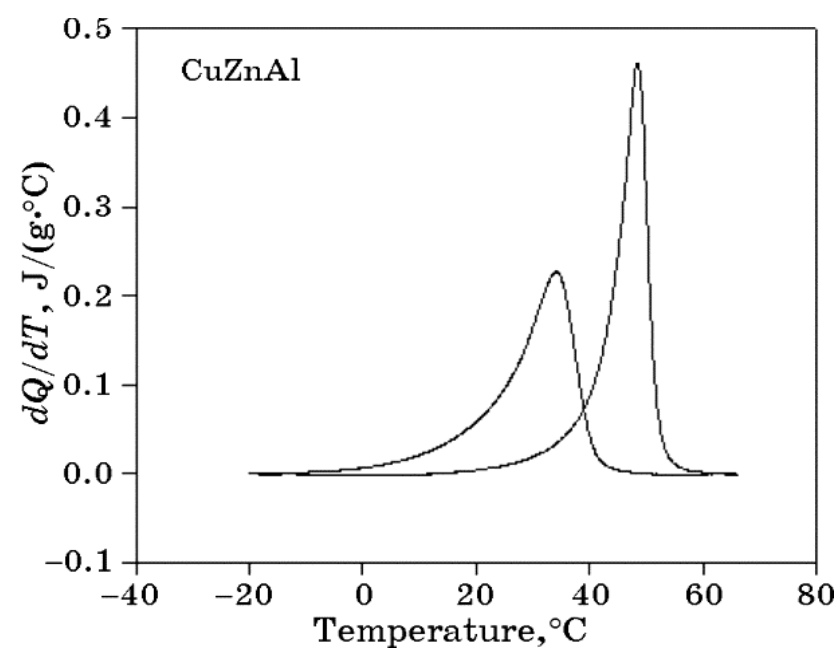

Fig. 1. The relative differential heat flow data extracted from DSC measurements in CuZnAl.

The initial data obtained has been also subjected to a special processing directed on the best extraction of the base-line effects. Second order polynomial base line parameters were found from the best-fit requirements with the measurement data in the temperature intervals corresponding to completely martensitic and austenitic states.

Then, these data were used to find the relative transformation entropy and relative fraction change during the complete cycle of

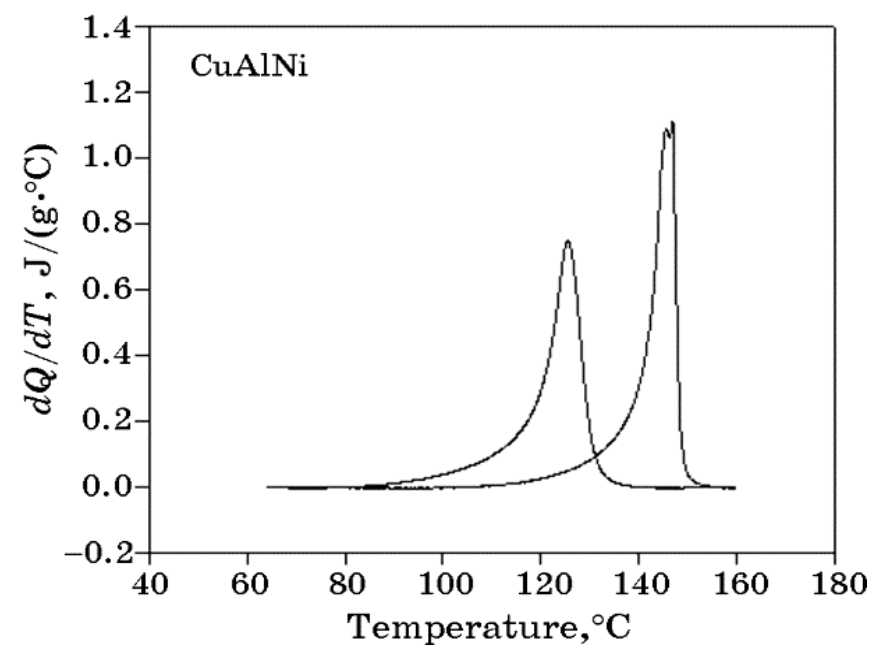

Fig. 2. The relative differential heat flow data extracted from DSC measurements in CuAlNi. 


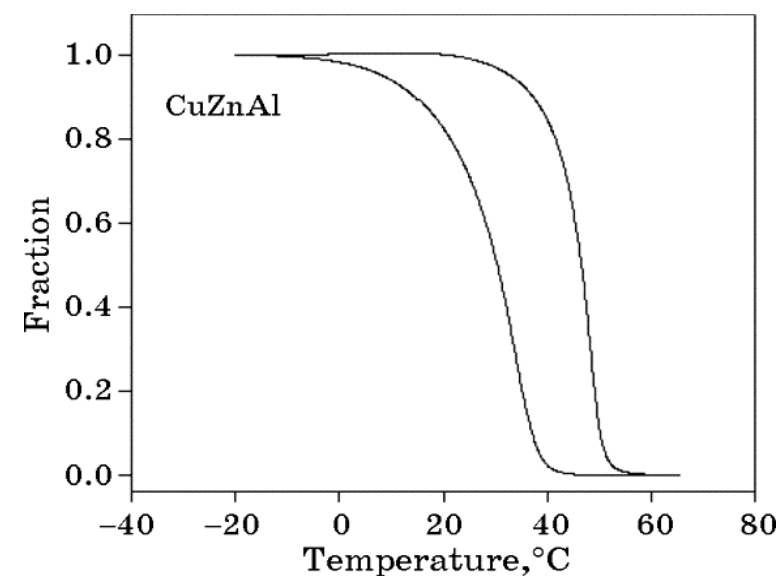

Fig. 3. The temperature dependence of martensite fraction obtained from the DSC measurement in CuZnAl.

transformation as a function of temperature (see Figs. 3 and 4).

The relative entropy change $\delta S_{ \pm}(T)=S\left(z_{ \pm}(T), T\right)-S_{a}(T)$ as a function of the temperature caused martensitic transformation along the global transformation cycle and its overall value $\Delta S$ have been found using the following equations:

$$
\delta S_{ \pm}(T)=-\int_{T}^{A_{f}} \frac{d T}{T} \frac{d Q_{ \pm}}{d T}, \Delta S_{ \pm}=-\int_{M_{f}}^{A_{f}} \frac{d T}{T} \frac{d Q_{ \pm}}{d T} .
$$

According to zero entropy production during the full direct and re-

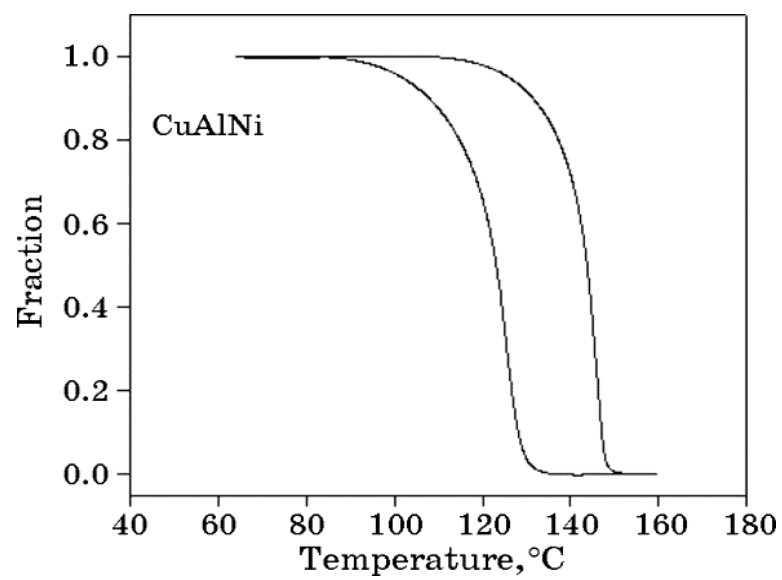

Fig. 4. The temperature dependence of martensite fraction obtained from DSC measurement in CuAlNi. 
verse martensitic transformation cycle, it is expected $\Delta S_{+}=\Delta S_{-}$. Experimentally found values were $\Delta S=0.011 \mathrm{~J} /(\mathrm{g} \cdot \mathrm{K})$ for alloy $A$ and $\Delta S=0.02 \mathrm{~J} /(\mathrm{g} \cdot \mathrm{K})$ for alloy $B$, respectively. The martensite fraction behaviour has been obtained by using the normalization method as $z_{+}(T)=\delta S_{+}(T) / \Delta S_{+}$and shown in Fig. 2. It should be noted that the definition of transformation entropy from the Eq. (14) are good in the limit of small heat capacity difference between the austenite and martensite. Ortin and Planes [13, 14] have analysed the more accurate procedure of the entropy calculation taking into account heat capacity effect in details. As follows from our analysis, the corresponding heat capacity corrections must be considered in the force balance equation too taking into account a weak temperature dependence of $\Delta U_{p}$ and $\Delta S$ in Eqs. (8) and (9). The pseudoequilibrium temperatures and transformation heats have been obtained according to Eqs. (11) and (12) and were $T_{0 p}=308.7 \mathrm{~K}$, $\Delta U_{p}=3.38 \mathrm{~J} / \mathrm{g}$ for alloy $A$ and $T_{0 p}=403 \mathrm{~K}, \Delta U_{p}=8.06 \mathrm{~J} / \mathrm{g}$ for alloy $B$, respectively. Finally, the fraction dependent residual nonchemical energies and dissipative forces have been calculated according to Eqs. (11) and (13) and represented in Figs. 5-8.

Therefore, using directly the first and second Thermodynamic Laws and without application of any minimization procedures, one can accurately derive the main thermodynamic force balance equations taking into account the energy dissipation processes caused by hysteresis.

The proposed scheme of splitting of the total amount of nonchemical energy into the pseudo-chemical component linearly dependent on the martensite fraction and a residual part of the

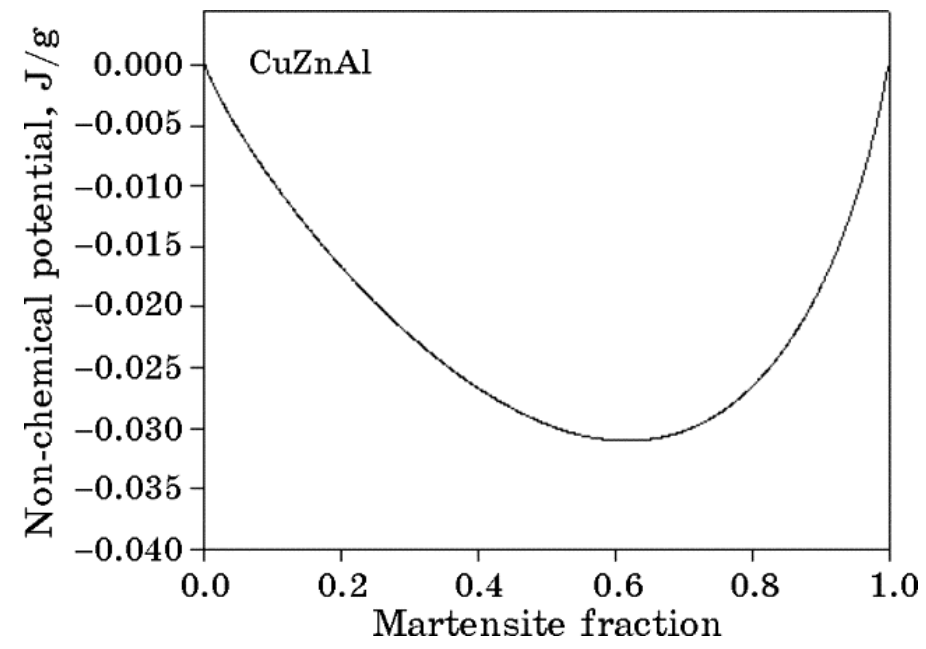

Fig. 5. Fraction dependence of the nonchemical potentials in $\mathrm{CuZnAl}$. 


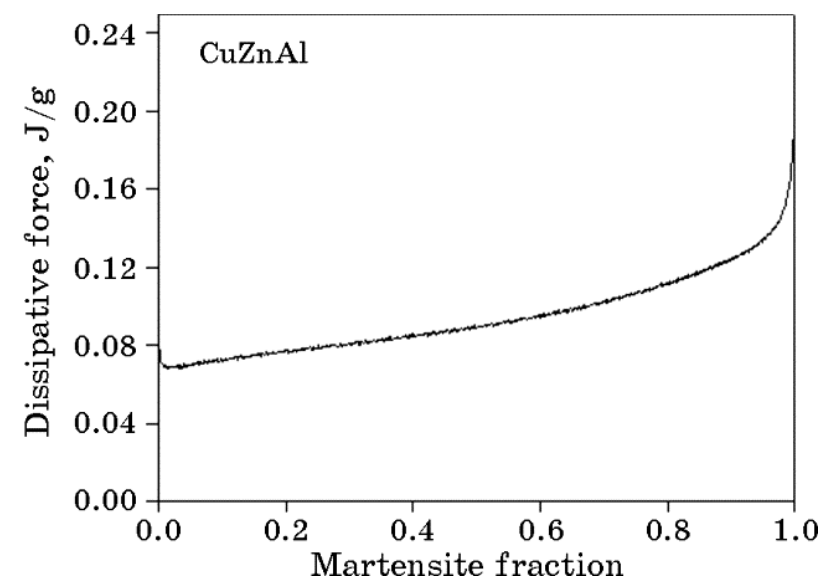

Fig. 6. Fraction dependence of the dissipative forces in $\mathrm{CuZnAl}$.

fraction dependent nonchemical energy has two physical reasons. As it was earlier mentioned, both the pure chemical and the total nonchemical energies are not directly measurable quantities in case of multi-variant temperature-induced martensitic transformation. Unlike to these, the linearly dependent on the martensite fraction contributions of chemical and nonchemical energies combined together as pseudo-chemical energy and the residual potential $\varphi(z)$ will remain the only really measurable quantities in absence information on $T_{0}$.

On the other hand, the linear contribution extracted from the total nonchemical energy and combined together with a similar linear term of chemical energy is responsible only for a simple renormali-

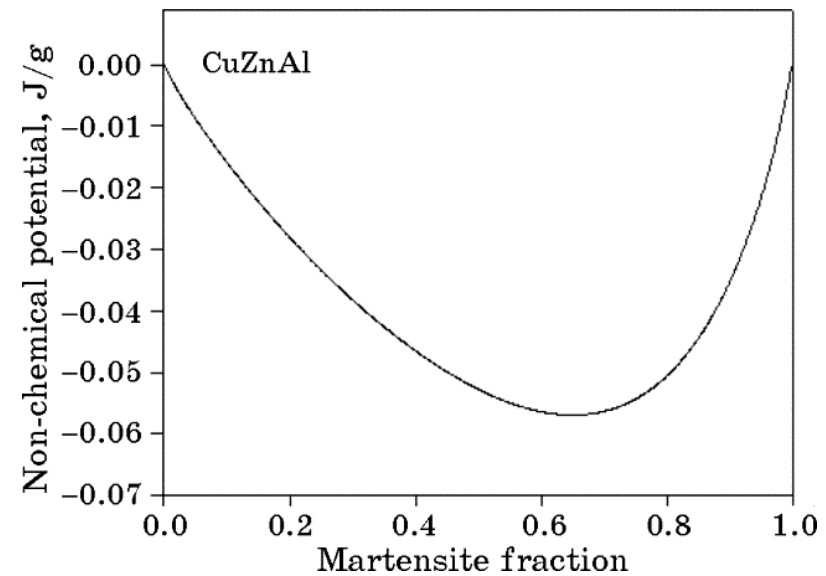

Fig. 7. Fraction dependence of the nonchemical potentials in CuAlNi. 


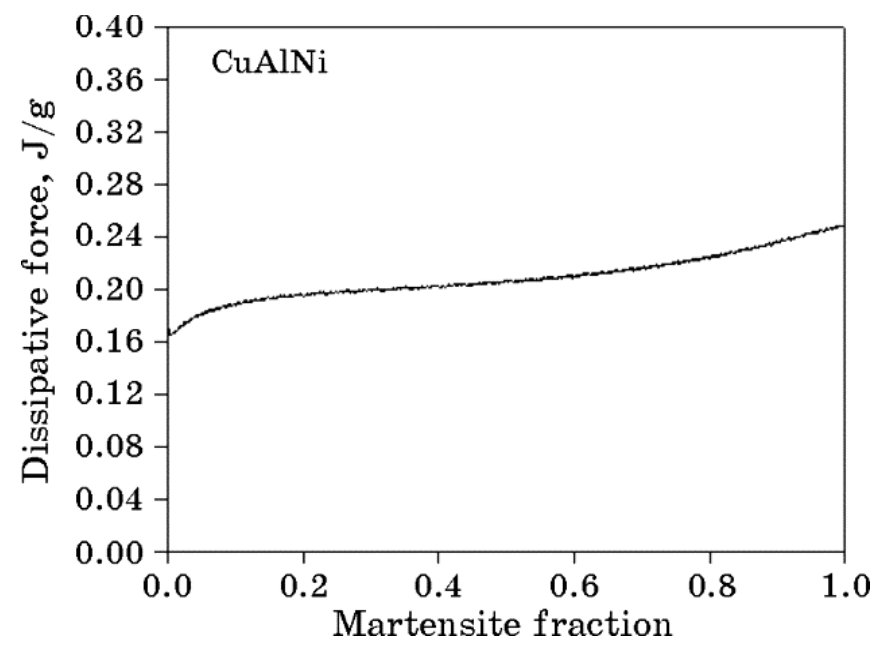

Fig. 8. Fraction dependence of the dissipative forces in $\mathrm{CuAlNi}$.

zation of the latent transformation heat value by a constant nonchemical energy stored in the completely martensitic state. As a result, the temperature $T_{0}$ is also shifted and replaced by the pseudo-chemical equilibrium temperature $T_{0 p}$ being defined by Eq. (12). Therefore, all the essential information on the thermoelastic equilibrium can be obtained from the detailed investigation of the residual nonchemical energy $\varphi(z)$ and its dependence on the martensite fraction. One can easily check the following general properties of this potential.

(i) Residual potential is always negative $\varphi(z)<0$ and takes zero values at $z=0$ and $z=1$.

(ii) $\varphi(z)$ has positive curvature: $\varphi^{\prime \prime}(z)=\Delta S T_{\mathrm{eq}}^{\prime}(z)>0$, because $\Delta S<0$ and $T_{\mathrm{eq}}^{\prime}(z)<0$.

(iii) $\varphi(z)$ has a single minimum, because $\varphi^{\prime}(z)=0$, if only $T_{\text {eq }}(z)=T_{0 p}$.

The item (ii) can be considered as the general thermodynamic stability condition of the thermoelastic hysteresisless equilibrium curve which must be always monotonically decreasing function of $z$ $\left(T_{\mathrm{eq}}^{\prime}(z)<0\right)$. It is important that the total nonchemical energy that differs from $\varphi(z)$ only by a linearly dependent on martensite fraction term must also satisfy this condition. In both cases experimentally analysed here and indicated in Fig. 5, one can observe the faster increase of the residual potential as $z \rightarrow 1$ and shift of its minimum to the martensitic phase side. It is assumed that such behaviour is a result of the inter-variant interactions when each newly formed martensitic crystal contacting with earlier formed multi-variant microstructure will produce an additional amount of elastic energy due to the incompatibility at the martensite- 
martensite interfaces. On the other side, these additional internal stresses will make the inter-variant boundaries to occupy the more appropriate positions producing, therefore, some additional amount of irreversible work. This effect is expected to be responsible for the significant fraction dependence of the dissipative force and austenite-martensite asymmetry of nonchemical potential, which is found for the $\mathrm{CuZnAl}$ alloy. In case of $\mathrm{CuAlNi}$ containing two types Ti-rich X-phase and $\gamma_{2}$-phase precipitates [16], both effects are present too, but increase of nonchemical energy becomes stronger nearly $z=1$, so as the fraction dependence of dissipative force is not so sharp in comparison to the CuZnAl alloy. This shows that different types of quenched inhomogeneities can essentially influence on the processes of nonchemical energy storage and thermoelastic properties of shape-memory alloys. In this sense, the investigation of microscopic mechanisms of thermoelastic equilibrium is one of the interesting problems for the martensitic transformation physics that have been partially discussed in [17-19]. Some ideas and results following from the analysis proposed there will be briefly reviewed in the next sections.

\section{INTERNAL STRESSES, QUENCHED INHOMOGENEITIES, AND THERMOELASTIC EQUILIBRIUM IN SHAPE-MEMORY ALLOYS}

It is known that a great number of shape-memory alloys, having the small temperature hysteresis, usually show thermoelastic behaviour. Macroscopically, the thermoelastic equilibrium can be considered as a coexistence of the martensite and parent phase in the wide temperature region between two characteristic temperatures, $M_{s}$ and $M_{f}$. Microscopically, the thermoelastic equilibrium is displayed as a self-accommodated ensemble of plate-like martensitic crystals, which can grow continuously on cooling and, correspondingly, disappear on heating. These continuous martensite microstructure variations are always accompanied with the corresponding martensitic volume fraction change [2].

From a general point of view, the thermoelastic equilibrium in SMAs can be considered as a result of the local balance between socalled 'chemical' driving forces and mechanical driving forces, which are connected with the elastic stress field. It is produced by the martensitic crystals system together with other stress field sources [20]. Although this conception of thermoelastic equilibrium nature has been generally accepted for a long while, no adequate mathematical methods have been proposed for solution of the problem.

Different types of so-called 'quenched' inhomogeneities are known 
to play an important role in martensitic transformation physics. First of all, the strongest effects are expected from the microscopic composition and ordering inhomogeneities, interstitial point defects, dislocations and stacking faults, grain boundaries, etc. that cannot relax in time and change rapidly their spatial configuration in a martensitic transformation temperature intervals.

Following [17-19], the main aim of the present section is to represent a general method for systematic analysis of the thermoelastic equilibrium states in SMAs. Here, we are taking into account the important role of the random internal driving forces produced by various randomly distributed elastic stress sources, including a selfconsistent incompatibility stress fields generated by the martensiteaustenite system.

Here, we will be restricted with a simple case when only a single variant of martensitic phase is realized. It is also considered a completely plane shear structure distortion matrix

$$
\hat{\varepsilon}=\left(\begin{array}{ccc}
1 & 0 & 0 \\
0 & -1 & 0 \\
0 & 0 & 0
\end{array}\right),
$$

which has two invariant shear planes with normal vectors $m_{1}=$ (110) and $m_{2}=(1 \overline{1} 0)$. Introduce the microscopic configuration function $\chi(x)$ to describe an arbitrary two-phase state containing a system of the multiple martensite-austenite interfaces. It is defined in such a way to have $\chi(x)=1$ and $\chi(x)=0$ values in martensite and austenite, respectively. Then one can easily express the inelastic strain distribution in the material as follows:

$$
\hat{\varepsilon}(x)=\hat{\varepsilon} \chi(x) \text {. }
$$

The definite amount of elastic energy $U_{e}[\hat{\varepsilon}(x)]$ is stored in the twophase state due to incompatibility of the martensite-structure lattice distortion with undistorted parent phase crystal structure. Accordingly, the internal stress field produced by a system of martensitic crystals ensemble in the material $\hat{\sigma}_{m}(x)$ can be found from the elastic energy functional as functional derivative:

$$
\hat{\sigma}_{m}(x)=-\frac{\delta U_{e}[\hat{\varepsilon}(x)]}{\delta \hat{\varepsilon}(x)} .
$$

By the way, it is important to take into account the elastic interaction energy between the martensite and different type defects producing inhomogeneous stress fields $\hat{\sigma}_{r}(x)$ in the material: 


$$
U_{r}[\hat{\varepsilon}(x)]=-\int d^{3} x\left(\hat{\varepsilon}(x) \times \hat{\sigma}_{r}(x)\right) .
$$

Therefore, the total Gibbs free energy of heterophase martensiteaustenite system in this case can be always written in the following form:

$$
G[\chi(x)]=\int d^{3} x g_{0}(x) \chi(x)+V[\chi(x)],
$$

where the first term represents the total chemical energy with the specific Gibbs free energy difference per unit volume between the martensite and austenite, $g_{0}(T)=G^{M}(T)-G^{A}(T)$. The second one $V[\chi(x)]$ is the nonchemical energy functional:

$$
V[\chi(x)]=U_{e}(x)+U_{r}[\hat{\varepsilon}(x)] .
$$

Taking the variational derivative of the total Gibbs free energy functional in respect to $\chi(x)$, one can define the local thermomechanical driving force applied to the martensite-austenite interface $\Gamma$ for $x \in \Gamma$ :

$$
g(x ; T)=g(T)+\frac{\delta G[\chi(x)]}{\delta \chi(x)}=g(T)-\hat{\varepsilon} \times\left(\hat{\sigma}_{m}(x)+\hat{\sigma}_{r}(x)\right) .
$$

The martensitic crystal ensemble can be in a thermomechanical equilibrium state only if the above-defined thermomechanical driving force will zero for all $x \in \Gamma$ at the inter-phase boundaries. In other words, the balance equation between the 'chemical' $g(T)$ and mechanical $\tau(x)$ driving forces is fulfilled at all the boundaries $\Gamma$ between the martensite and parent phase. That is

$$
g(T)=\tau(x) \text { if } x \in \Gamma .
$$

Here,

$$
\tau(x)=\hat{\varepsilon} \times \hat{\sigma}(x) .
$$

$\hat{\varepsilon}$ is the shear distortion matrix associated with the martensitic transformation of the parent phase lattice structure, and $\hat{\sigma}(x)$ is the total internal stress tensor caused both the martensite crystal system and other randomly distributed sources of the elastic stress. In particular, it is important that in equilibrium the martensitic phase can occupy that region of space where $g(T)<\tau(x)$.

In other words, the equilibrium spatial distribution of the martensitic phase can be explicitly expressed by the configuration function $\chi(x)$ : 


$$
\chi(x)=\eta(\tau(x)-g),
$$

which takes the values $\chi(x)=1$ in the region occupied by martensite and $\chi(x)=0$ in the parent phase region, respectively. Here, $\eta(\xi)$ is the well-known Heaviside function:

$$
\eta(\xi)=\left\{\begin{array}{l}
1 \text { for } \xi>0 \\
0 \text { for } \xi<0
\end{array}\right.
$$

In general, the total internal stress $\hat{\sigma}(x)$ may be expressed as a superposition

$$
\hat{\sigma}(x)=\hat{\sigma}_{m}(x)+\hat{\sigma}_{r}(x),
$$

where $\hat{\sigma}_{m}(x)$ is the stress field associated with the martensitic crystals ensemble and $\hat{\sigma}_{r}(x)$ is caused by the random defect system. Similarly, in accordance with Eq. (23), the mechanical driving force $\tau(x)$ can be written as

$$
\tau(x)=\tau_{m}(x)+\tau_{r}(x) .
$$

Using the elasticity theory, the martensitic stress field $\hat{\sigma}_{m}(x)$ can be found as a linear functional of the martensitic configuration function $\chi(x)$ [21]. The corresponding result can be expressed in the following general form:

$$
\sigma^{\alpha \beta}(x)=-\hat{E}^{\alpha \beta} \chi(x),
$$

where the evident form of the integral-differential linear operators $\hat{E}^{\alpha \beta}$ follows immediately from the direct solution of the theory elasticity equations. In particular, the martensitic component of the mechanical driving force $\tau_{m}(x)$ has the following form:

$$
\tau_{m}(x)=-\hat{E} \chi(x),
$$

with $\hat{E}=\varepsilon_{\alpha \beta} \hat{E}^{\alpha \beta}$. Combining the Eqs. (24), (27), and (29), one can obtain a self-consistent nonlinear thermoelastic equilibrium equation for the mechanical driving force $\tau(x)$ :

$$
\tau(x)=\tau_{r}(x)-\hat{E} \eta(\tau(x)-g) .
$$

It should be also noted that the linear operator $\hat{E}$ has a diagonal form in the Fourier representation. That is, the plane waves $\exp (i k x)$ corresponding to the wave-vector $\mathbf{k}$ are evidently the eigenfunctions of $E$ : 


$$
\hat{E}\left(e^{i k x}\right)=\lambda(n)\left(e^{i k x}\right),
$$

where the eigenvalues $\lambda(n)$ are always the positive functions, depending only on the direction vector $\mathbf{n}=\mathbf{k} /|\mathbf{k}|$ in $\mathbf{k}$-space. In special cases, if the structure distortion matrix $\hat{\varepsilon}$ can be represented as the invariant plane shear with the shear plane normal vectors $m_{1}$ or $m_{2}$, then

$$
\lambda(n)=G \varepsilon^{2} f(n),
$$

where $G$ is the shear modulus, $\hat{\varepsilon}$ is the structure strain value and $f(n)$ is the dimensionless positive function taking zero value $f(n)=0$ if $n=m_{1}$ or $m_{2}$.

\section{SOLUTION AND ANALYSIS}

The thermoelastic equilibrium Eq. (30) cannot be solved exactly because of the nonlinear term in the right side of the Eq. (30). However, an effective approximation method based on the linearization of the nonlinear term in the Eq. (30) has been proposed in Ref. [18]. In accordance with that one, the configuration function $\eta(\tau(x)-g)$ is approximated as follows:

$$
\eta(\tau(x)-g) \approx z(g)+P(g) \tau(x),
$$

where the identification of the coefficients $z(g)$ and $P(g)$ can be found from the evident equations:

$$
z(g)=\langle\eta(\tau(x)-g)\rangle, P(g)=\left\langle\frac{\delta}{\delta \tau(x)} \eta(\tau(x)-g)\right\rangle,
$$

after $\langle\ldots .$. -averaging the configuration function $\eta$ and its first derivative value $\delta \eta / \delta \tau$. Both parameters $z(g)$ and $P(g)$ have an evident physical interpretation. In particular, function $P(\tau)$ represents the probability distribution function of the mechanical driving force field $\tau(x)$. Here, $\delta(\xi)=d \eta(\xi) / d \xi$ is the well-known Dirac's function. Besides, $z(g)$ represents the volume fraction of martensite as a function of 'chemical' driving force $g$. As a result of Eq. (33),

$$
\hat{E} \eta(\tau(x)-g) \approx P(x) \hat{E} \tau(x),
$$

because the action of $\hat{E}$ on the spatially homogeneous function $z(g)$ gives 0. Substituting Eq. (35) into Eq. (30), one can obtain the linearized thermoelasticity equation for a self-consistent mechanical driving force $\tau(x)$ : 


$$
(\hat{I}+P(g) \hat{E}) \tau(x)=\tau_{r}(x) .
$$

A simple relationship between the Fourier transform coefficients $\tau(k)$ and $\tau_{r}(k)$ of $\tau(x)$ and $\tau_{r}(x)$ follows immediately from Eqs. (31), (32), and (36). As a result, the solution of the self-consistent thermoelastic equilibrium Eq. (30) can be expressed in the following analytic form:

$$
\tau(k)=\tau_{r}(k)(1+\xi(g) f(n))^{-1},
$$

where $\xi(g)=G \varepsilon^{2} P(g)$. The linear relation between $\tau(k)$ and $\tau_{r}(k)$ denotes that the random self-consistent field $\tau(x)$ can be considered as a Gaussian random field only if $\tau_{r}(k)$ is also Gaussian. In particular, the probability distribution function $P(\tau)$ can be expressed as follows:

$$
P(\tau)=\left(2 \pi\left\langle\tau^{2}\right\rangle\right)^{-1 / 2} \exp \left\{-\tau^{2} /\left\langle\tau^{2}\right\rangle\right\}
$$

where the statistical dispersion $\left\langle\tau^{2}\right\rangle$ of $\tau(x)$ and $\xi(g)$ can be found from the Eqs. (37) and (39):

$$
\left\langle\tau^{2}\right\rangle=\int d^{3} k|\tau(k)|^{2} .
$$

Here, $|\tau(k)|^{2}$ is the Fourier power spectrum of $\tau(x)$. Using Eq. (37) and substituting it into Eq. (39), one can obtain the equations determining the dependence of $\xi(g)$ and $\left\langle\tau^{2}\right\rangle$ on the 'chemical' driving force, respectively. As follows from our analysis, the functions $\xi(g)$ and $\left\langle\tau^{2}\right\rangle$ show the following properties:

$$
\begin{gathered}
\left\langle\tau^{2}\right\rangle \underset{g \rightarrow 0}{\longrightarrow}(1 / 4) \rho^{-1}\left\langle\tau_{r}^{2}\right\rangle,\left\langle\tau^{2}\right\rangle \underset{g \rightarrow \pm \infty}{\longrightarrow}\left\langle\tau_{r}^{2}\right\rangle, \\
\xi \underset{g \rightarrow 0}{\longrightarrow} 2 \rho^{2}, \xi \underset{g \rightarrow \pm \infty}{\longrightarrow} 0 .
\end{gathered}
$$

Here,

$$
\rho=G \varepsilon^{2}\left(\left\langle\tau_{r}^{2}\right\rangle\right)^{-1 / 2},\left\langle\tau_{r}^{2}\right\rangle=\int d^{3} k\left|\tau_{r}(k)\right|^{2} .
$$

Because $\left\langle\tau_{r}^{2}\right\rangle=\left\langle\left(\varepsilon \sigma_{r}(x)\right)^{2}\right\rangle=\varepsilon^{2}\left\langle\left(\sigma_{r}(x)\right)^{2}\right\rangle$, then an important parameter $\rho$ can be expressed as a ratio $\rho=\varepsilon / \varepsilon_{r}$ between the structure distortion $\varepsilon$ and elastic strain level $\varepsilon_{r}$ corresponding to the internal stress field $\hat{\sigma}_{r}(x)$ :

$$
\varepsilon_{r}=G^{-1}\left(\left\langle\sigma_{r}^{2}(x)\right\rangle\right)^{1 / 2}
$$




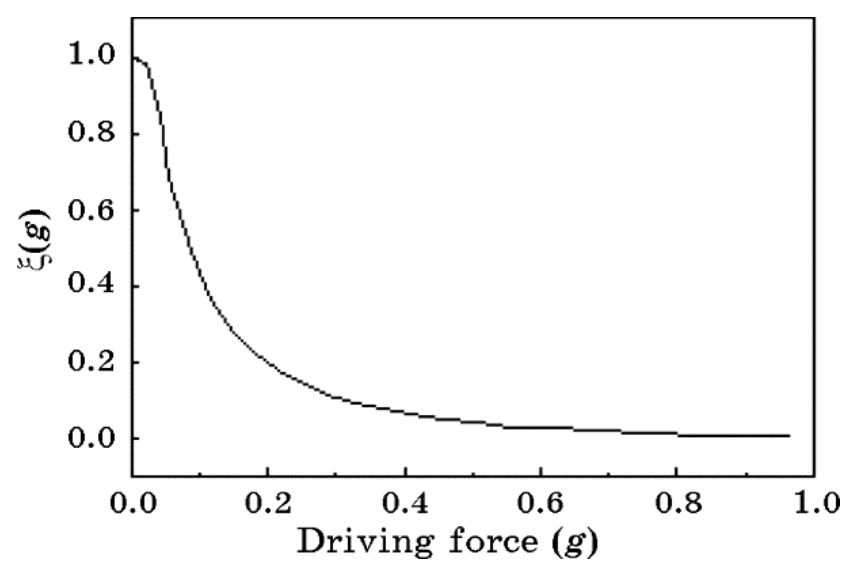

Fig. 9. Normalized value of $\xi(g)$ as function of chemical driving force.

Only the large values of $\rho$ can be a subject of analysis because, in most of cases, $\varepsilon_{r}$ is much smaller than the structure distortion parameter $\varepsilon$. The quantitative representation of $\xi(g)$ and $\left\langle\tau^{2}\right\rangle$ behaviour are shown in Figs. 9, 10. Here, $g$ is represented in units $\sqrt{\tau_{r}^{2}}$.

Some interesting conclusions follow immediately from the simplest analysis of Eq. (37). In particular, one can conclude that the Fourier power spectrum $|\tau(k)|^{2}$ is always localized in that region of $\mathbf{k}$-space where the angle $\theta$ between $\mathbf{n}$ and shear plane normal vector $\mathbf{m}_{1}\left(\right.$ or $\left.\mathbf{m}_{2}\right)$ takes the small values:

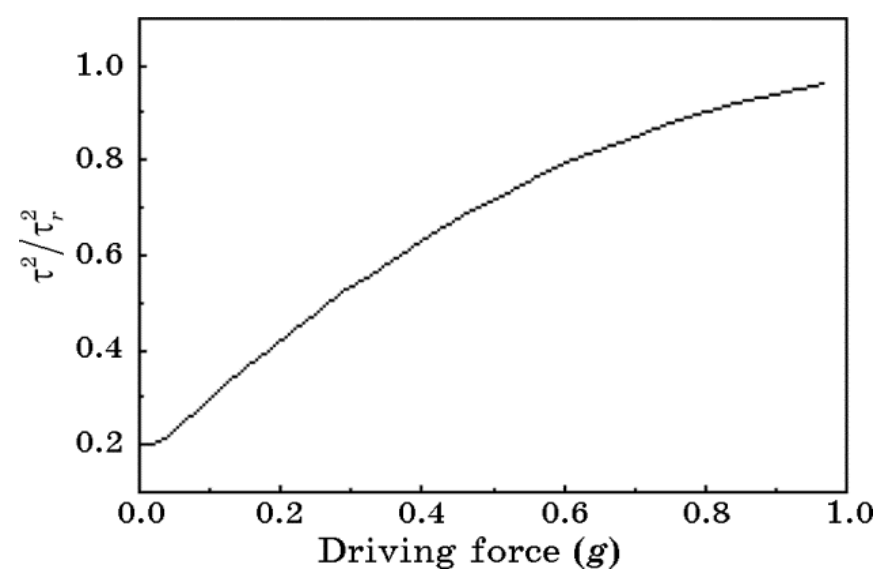

Fig. 10. Relationship between mean square nonchemical and chemical driving forces. 


$$
|\theta|<\xi^{-1 / 2}(g), \theta=(\mathbf{n}, \mathbf{m}) .
$$

A similar anisotropic Fourier power spectrum distribution is known to be a consequence of the plate-like structure of martensite in real space. In particular, the habit planes of martensitic plates will coincide with the shear planes of the structure distortion, and the average thickness and radius of the plates can be estimated as

$$
d=\lambda_{0}, R=\lambda_{0} \xi^{1 / 2}(g) .
$$

Therefore, the plate radius can strongly increase on cooling and approach the largest value $R_{\max }=\lambda_{0} \rho$ at $g=0$. Here, $\lambda_{0}$ is the characteristic spatial scale of the random stress field $\hat{\sigma}_{r}(x)$.

The martensitic volume fraction as a function of 'chemical' driving force $g$ can also be obtained from the present theory. The corresponding results are represented in Eq. (34).

$$
z(g)=\langle\chi(x)\rangle=\operatorname{erf}\left(g^{2} /\left\langle\tau^{2}\right\rangle\right) .
$$

Here, the brackets $\langle\ldots\rangle$ denote the statistical averaging procedure and $\operatorname{erf}(p)$ is a well-known 'error function'. The graphic representation of volume fraction behaviour is shown in Fig. 11, where $g$ is represented in units of $\sqrt{\tau_{r}^{2}}$. In particular, the martensitic transformation interval for chemical driving force $\Delta g$ can be estimated as

$$
\Delta g=\left(\left\langle\tau^{2}\right\rangle\right)^{1 / 2}=\rho^{-2} G \varepsilon^{2}
$$

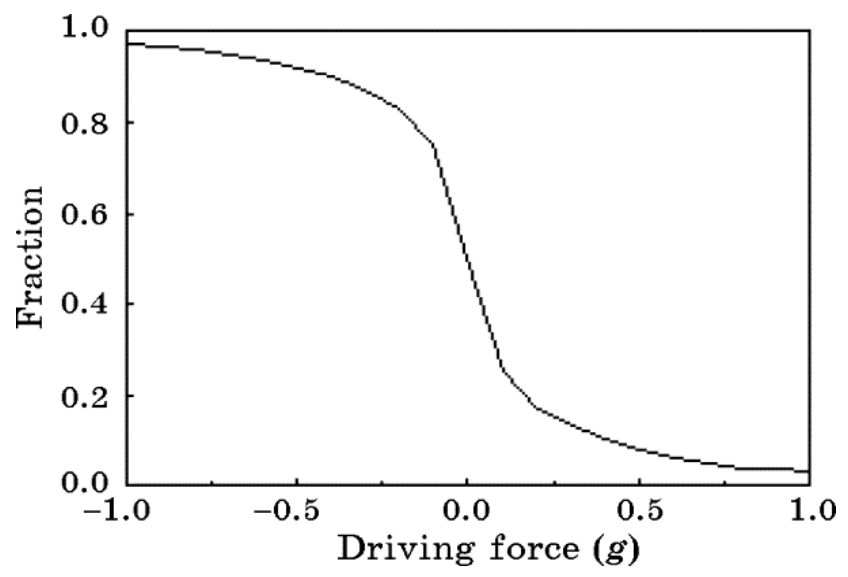

Fig. 11. Martensite fraction as function of chemical driving force change. 


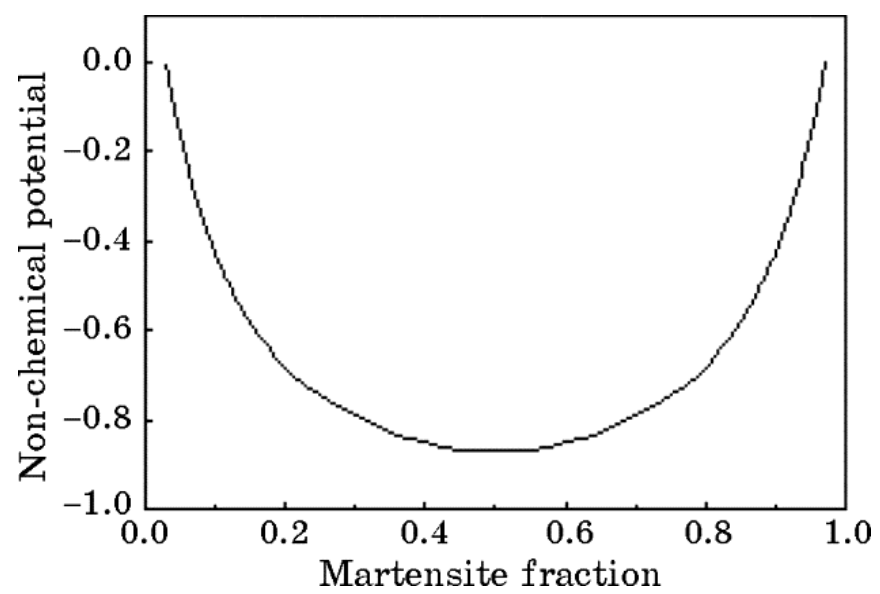

Fig. 12. Nonchemical energy and its fraction dependence calculated within the present model.

and considered as a characteristic energy scale for the nonchemical interactions. The total nonchemical energy and its martensite fraction dependence has been also calculated and plotted in Figs. 11, 12. The nonchemical energy is given in units of $\Delta g$. These model calculations are in good qualitative agreement with the residual nonchemical energy behaviour obtained from DSC measurement and discussed in the preceding sections. Naturally, the experimentally found asymmetric shape of the fraction dependent potentials mainly connected with the inter-variant interaction effects cannot be satisfactorily reproduced in the framework of present single variant model. Similar effects are assumed to be a subject of further developments in this field of investigations.

Therefore, in accordance with the present studies, the random stress fields produced by the different quenched defects in parent phase play an important role in thermodynamic driving force balance. They and should be always taken into account to understand the nature of thermoelastic equilibrium and to describe quantitatively the macroscopic and microstructure properties of SMAs.

\section{REFERENCES}

1. $\quad$ G. V. Kurdjumov, Tech. Phys. U.S.S.R., 18: 999 (1949).

2. G. V. Kurdjumov and L. C. Khandros, Dokl. Acad. Nauk. SSSR, 66: 211 (1949) (in Russian).

3. G. V. Kurdjumov, J. Metals, 11: 449 (1959).

4. L. Delaey, R. V. Krishnan, H. Tas, and H. Warlimont, J. Mater. Sci., 9: 1521 (1974). 
5. R. V. Krishnan, L. Delaey, H. Tas, and H. Warlimont, J. Mater. Sci., 9: 1536 (1974).

6. H. Warlimont, L. Delaey, R. V. Krishnan, and H. Tas, J. Mater. Sci., 9: 1536 (1974).

7. G. B. Olson and M. Cohen, Scr. Metall., 9: 1247 (1975).

8. G. B. Olson and M. Cohen, Scr. Metall., 11: 345 (1977).

9. H. C. Tong and C. M. Wayman, Acta Metall., 22: 887 (1974).

10. C. M. Wayman and H. C. Tong, Scr. Metall., 11: 341 (1977).

11. Y. I. Paskal and L. A. Monasevich, Sov. Phys. J., 78: 1466 (1979).

12. Y. I. Paskal and L. A. Monasevich, Phys. Met. Metall., 52: 95 (1981).

13. J. Ortin and A. Planes, Acta Metall., 36: 1873 (1988).

14. J. Ortin and A. Planes, Acta Metall., 37: 1433 (1989).

15. C. Segui, E. Cesari, and J. Pons, Mater. Trans., JIM, 33: 650 (1992).

16. E. Cesari, C. Segui, J. Pons, and F. Perelló, J. Phys. IV France, 6, C8: 413 (1996).

17. A. A. Likhachev and Yu. N. Koval, Samosoglasovannye Polya Napryazheniy $i$ Termouprugoe Ravnovesie Faz v Neodnorodnykh Tverdykh Rastvorakh [The Self-Consistent Field Stresses and Thermoelastic Phase Equilibrium in Heterogeneous Solid Solutions] (Kiev: 1988) (Prepr./N.A.S. of Ukraine. Inst. for Metal Physics. No. 20.88, p. 18) (in Russian).

18. A. A. Likhachev and Yu. N. Koval, Scr. Metall. Mater., 27: 1623 (1992).

19. A. A. Likhachev and Yu. N. Koval, Fazovye Prevrashcheniya Martensitnogo Tipa [Martensitic-Type Phase Transformations] (Kiev: Naukova Dumka: 1993), p. 39-52 (in Russian).

20. A. L. Roytburd, Usp. Fiz. Nauk, 113: 69 (1974) (in Russian).

21. A. G. Khachaturyan, Fiz. Tverdogo Tela, 8: 2709 (1966) (in Russian). 